\title{
PRÁTICAS DO ENSINO DE HISTÓRIA MEDIEVAL: CONHECENDO AS MENTALIDADES
}

\author{
Álvaro Nonato Franco Ribeiro ${ }^{1}$ \\ Sônia Aparecida Siquelli²
}

\section{Resumo}

Este artigo tem como objetivo compreender como os professores da rede pública e privada do Ensino Fundamental de História, da cidade de Pouso Alegre/MG percebem, e incorporam características do ideário neoliberal de educação, em sua prática de ensino nas temáticas relacionadas à Idade Média. Presentes nos Parâmetros Curriculares Nacionais - PCN e no Currículo Básico Comum - CBC/MG propõem, através da adoção de práticas típicas da economia de mercado, desenvolver um sistema educacional pautado na qualidade. Para o ensino de História determinam a inclusão das fontes históricas em sala de aula, priorizar o desenvolvimento de habilidades e competências, que preparem o estudante para o mundo do trabalho. Trabalhou-se com o conceito de Nova História, mentalidades e da evolução das ideais pedagógicas no Brasil, descreve como as visões que permeiam as mentalidades e do medievo são resultados de um longo processo de formação das mentalidades. Foi possível levantar categorias que permitiram descrever como as fontes históricas estão incorporadas ao ensino de História Medieval na prática docente.

Palavras-chave: Ensino de história. Fontes históricas. Idade Média.

\section{PRACTICES OF MEDIEVAL HISTORY TEACHING: KNOWING THE MENTALITIES}

\begin{abstract}
This article aims to understand how teachers from public and private elementary school of history, the city of Pouso Alegre / MG realize, and incorporate features of the neoliberal ideology of education in their teaching practice on issues related to the Middle Ages. Present in the National Curriculum Proposals - PCN and Curriculum Common Basic - CBC / MG propose, through the adoption of practices typical of a market economy, develop an educational system founded on the quality. For the teaching of history determine the inclusion of historical sources in the classroom, prioritize the development of skills and competencies, which prepare students for the world of work. Worked with the concept of New History, mentalities and the development of teaching ideals in Brazil, describes how the views that permeate the minds and the Middle Ages are the result of a long process of formation of mentalities. It was possible to categories that allowed to describe the historical sources are incorporated into the Medieval History of education in teaching practice.
\end{abstract}

Keywords: History teaching. Historical sources. Middle Ages. 


\section{INTRODUÇÃO ${ }^{3}$}

Como perspectiva teórica metodológica para compreensão do objeto em estudo partiu-se da visão Le Goff (1990) que entende que todo documento, e aqui pode ser incluído o discurso dos docentes obtido através dos questionários, possui diferentes intencionalidades, e por isso, implícito no contexto que levou a sua construção, para assim ser compreendido. No caso, o contexto que construiu as visões acerca do ensino se relaciona ao projeto de educação burguesa, consolidado desde no século XIX e que afeta a educação brasileira atual, de acordo com Saviani (2006, 2008a, 2008b, 2013), e acaba por levar à construção de visões específicas no inconsciente coletivo ${ }^{4}$, no nível das mentalidades, no que diz respeito ao ensino de História e sobre a Idade Média.

Este artigo realizado a partir de uma pesquisa caracterizada como qualitativa, de caráter documental e empírico. Realizada para compreender como os professores de História das diferentes redes de ensino existentes na cidade de Pouso Alegre/MG incorporam, resistem e constroem suas práticas de ensino a partir das orientações da documentação curricular oficial, no que diz respeito às fontes históricas e sobre a Idade Média.

As fontes históricas muito contribuem para o ensino de História, uma vez que permitem ao professor explorar juntamente com seus alunos aspectos que muitas vezes aparecem negligenciados no material didático e até mesmo no discurso dos docentes. A sua utilização permite o aparecimento de novos sujeitos sociais, tramas que foram desprezadas na construção historiográfica e, por consequência, novas interpretações. No entanto, essas possibilidades podem ser reduzidas se o professor tratar esses documentos de forma acrítica, de modo que apenas reproduza a versão dos fatos já consolidados na memória oficial.

No que diz respeito à Idade Média, a reprodução de aspectos negativos já se consolidou como algo comum. A utilização das fontes históricas pode demonstrar ao aluno as muitas faces desse período e desconstruir essas visões generalizantes e preconceituosas, que acabam por afastá-lo de nosso cotidiano, reforçando apenas as suas características pejorativas. De acordo com Le Goff (2008), a compreensão do período medieval não pode ser realizada se houver a abstenção da visão ligada apenas às trevas ou que trate apenas de aspectos positivos, desprovidos de conflitos. O medievo, como qualquer outro período histórico, possuiu momentos com as duas características.

No entanto, quando se trata do ensino desse período histórico, não é isso o que se percebe. $\mathrm{O}$ ensino da Idade Média acaba reproduzindo as mesmas temáticas, que não desconstroem as características pejorativas desse momento histórico. Configura-se o medievo, segundo Le Goff (2006), como um período de parco desenvolvimento cultural, e intensidade de conflitos armados, que provocavam uma sensação geral de insegurança. $\mathrm{O}$ feudalismo é tratado como um sistema universal sem as particularidades apresentadas em cada um dos locais que se desenvolveu e aparece associado à construção de um modo de vida pautado pela exploração do campesinato, pela nobreza detentora do poder e das terras e pelo clero católico.

Estas características representam alguns dos elementos que são reproduzidos em sala de aula e que levam o aluno a construir uma visão negativa do período medieval. O ensino de História não pode se prender a estereótipos que classificam o período como bom ou mau, 


\section{Revista HIISTEXIDBR Dn-lime}

positivo ou negativo, e sim promover a aprendizagem de forma a levar o aluno a conhecer a complexa dinâmica que se constitui a sociedade em qualquer período histórico. Entende-se, que sejam contemplados, entre outros aspectos, o âmbito da cultura popular medieval, seus aspectos literários, a diversidade das relações entre senhores e camponeses, as diferentes formas de organização e desenvolvimento do sistema feudal. No momento dos estudos, seja focado o que contribua para que o aluno tenha acesso às contradições que se manifestam na história e que diversificam o contexto histórico.

Como exemplo desta situação apresentada, observa-se no livro didático adotado em algumas escolas da rede pública de Pouso Alegre - MG, através do Plano Nacional do Livro Didático - PNLD, de 2005 a 2007, intitulado História Crítica, do autor Mario Schmidt. Nele é possível observamos as cores escuras, seja no céu, nas paredes do castelo e principalmente no interior dessa construção, como se ao entrar nela, se defrontaria apenas com a escuridão. Percebe-se aqui a associação realizada entre o medievo e a "Idade das Trevas".

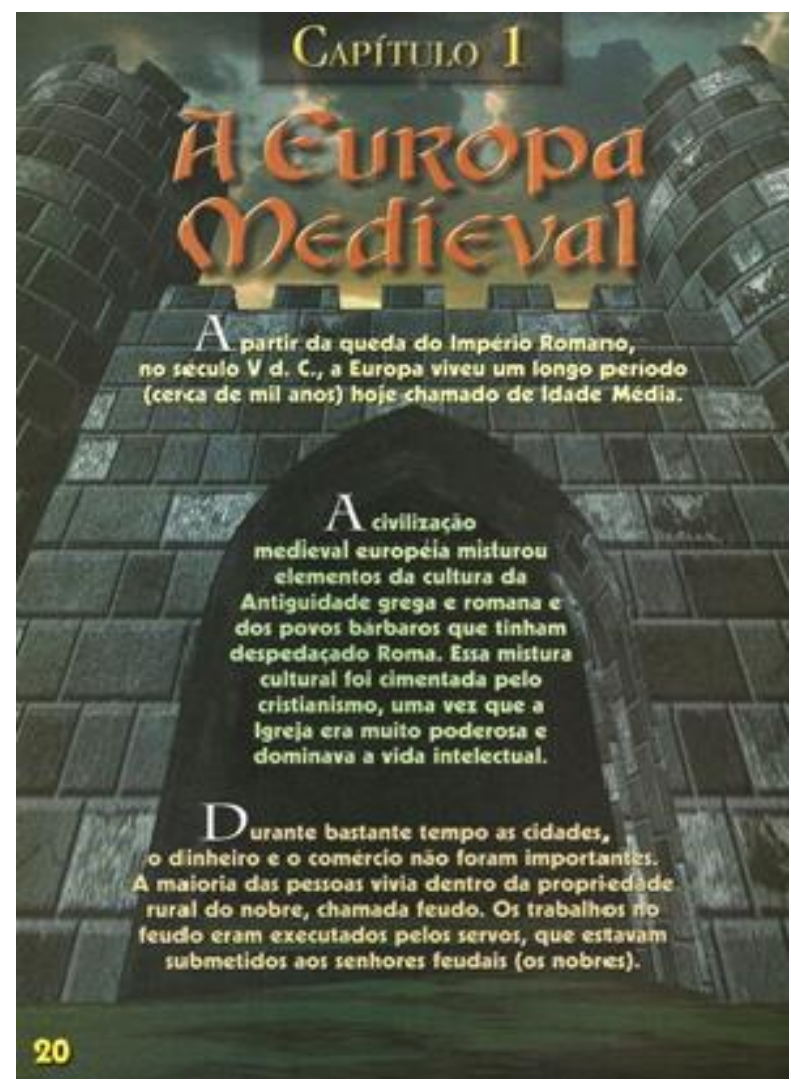

Figura 1 - A Europa Medieval.

Fonte: SCHMIDT, 2002.

Nos textos apresentados junto à imagem, é possível observar o papel conferido à Igreja Católica como a instituição dominante da cultura, sendo excluído o rico domínio da cultura popular. Além disso, é possível constatar a submissão do campesinato em relação aos senhores feudais, desprezando as diversas formas de manifestação das relações entre senhores e camponeses e as formas que esse grupo adotou para resistir e reorganizar o seu meio social. 
Neste contexto, compreende- se na prática desenvolvida pelo professor de História no Ensino Fundamental II, estava presente o ato de se reportar às fontes históricas, enquanto um dos meios de efetivar o processo de ensino e aprendizagem, quando se trata do período medieval. Buscou-se ainda descobrir se a utilização desses documentos contribui ou não para a construção de novos olhares a respeito do medievo ou se leva à reprodução das visões pejorativas que foram discutidas anteriormente.

De acordo com o material levantado durante a aplicação da pesquisa empírica, foi possível constatar de imediato que as fontes históricas estavam inclusas na prática dos professores, mas que eram incorporadas de forma acrítica, não sendo exploradas as múltiplas possibilidades que elas oferecem para o ensino de História. Acabam por ser incorporadas de forma ilustrativa, para reafirmar as visões já consolidadas.

Foi observado e constatado, a partir dessa leitura imediata do material levantado, que as fontes históricas constituem um elemento da prática de ensino dos professores de História, mas que são pouco exploradas frente às possibilidades que elas trazem consigo. Essas questões foram o que moveram a análise da pesquisa empírica aplicada.

Para atingir o objetivo geral determinado e responder a problemática enunciada anteriormente, foi construído um encaminhamento metodológico para a pesquisa, que levasse a relação existente entre a prática de ensino do professor de História e a utilização das fontes históricas. Relação esta que pode ser construída de duas formas. Ou tende à análise acrítica dos documentos, levando à construção de uma análise que apenas reproduza os fatos já cristalizados na memória social pelo material didático e pela fala dos docentes. Ou uma relação que leva à descoberta de outra história emanada dessas fontes documentais. Assim sendo, foi realizada uma pesquisa de campo junto aos professores de História que atuam no Ensino Fundamental.

Foram aplicados vinte e cinco (25) questionários a professores das redes de ensino pública e privada da cidade de Pouso Alegre - MG, com o objetivo de conhecer as práticas pedagógicas por eles construídas e buscar entender como elas são afetadas pela documentação oficial imposta pelo Estado ao cotidiano escolar.

\section{A HISTÓRIA DA EDUCAÇÃO BRASILEIRA SOB A ÓTICA DAS MENTALIDADES}

As mudanças passadas pela ciência histórica na primeira metade de século vinte trouxeram para o seu âmbito perspectivas de análises que até então haviam sido exploradas de modo isolado, sem estar associadas a um processo de transformação da história. Para Le Goff (1998) aqueles historiadores que se engajaram na renovação historiográfica buscaram superar a história fragmentada, puramente política e a factual, e construir um processo de pesquisa histórica, que trouxesse uma nova visão sobre o passado das sociedades.

Estes buscaram em seus trabalhos abordagens econômicas e sociais, que contribuíssem para a construção de uma história total, ou seja, uma história que trouxesse todos os aspectos que interferem no cotidiano de um povo. Assim sendo, novas possibilidades de trabalho foram abertas. Outros temas, fontes históricas e perspectivas de 


\section{Revista HIISTEYIDIR On-line}

análises adentraram no campo historiográfico e promoveram uma verdadeira revolução na sua prática.

A partir dessa prática inovadora, passou-se a considerar que a sociedade se assentava em estruturas, mecanismos que a organizavam e que dariam coerência às relações humanas que se operam em seu meio. Elas não poderiam ser percebidas em uma perspectiva temporal curta, preocupada apenas com acontecimentos isolados no tempo e no espaço, afirma Le Goff (1990).

A evolução e a existência das estruturas estão, portanto, associadas à longa duração, ou seja, a um período de tempo que foge dos anos precisos que caracterizavam os fatos da história positivista e se perde em meio aos séculos. Corresponde a uma construção histórica que foge do domínio daquilo que é consciente aos seres humanos. Práticas culturais que, para Vovelle (1998), de tão repetitivas se tornam automáticas, pouco analisadas, como por exemplo, as relações familiares, os sentimentos em torno da morte e do amor.

Este tempo longo permite compreender como a sucessão e reorganização das estruturas levou à construção de visões específicas acerca do mundo e que são carregadas pelos homens para dar sentido às relações operadas em seu meio. Desse modo, pode-se perceber que o domínio das estruturas é mais claramente visualizado quando é adotada a perspectiva de análise de toda uma comunidade, não se dissociando dela nenhum indivíduo. Quando tomamos como base toda a sociedade, podemos observar que muitos dos comportamentos e atitudes se reproduzem, no domínio do cotidiano, independentes da posição social desse indivíduo. É aquilo que liga um povo, acredita Le Goff (1995).

A reorganização das estruturas existentes só é possível quando ocorre um processo revolucionário, afirma o medievalista. Como exemplificação desse fato, pode-se retomar a ideia sobre a existência de uma longa Idade Média, que se estende do século V até o XVIII. Segundo este historiador, só através do processo da Revolução Francesa, ocorrido nos anos finais do século XVIII, que a sociedade europeia teria sido reestruturada, a partir da perda de força dos valores constituídos no mundo medieval, como a honra e a fidelidade. Ou seja, apenas através do processo das revoluções burguesas, que um novo modelo de sociedade começa a se delinear, modelo do qual somos herdeiros diretos.

A forma de abordagem tratada no tema de pesquisa até este momento, para o âmbito educacional e da constituição dos sistemas de ensino tal qual se apresentam hoje em nosso país, torna possível compreender que muito das visões que perpassam as mentalidades acerca da educação e sua importância, foram construídas pela sucessão e reorganização de estruturas ao longo da história da educação brasileira. Segundo Saviani (2008a), através da evolução das ideias pedagógicas que foram implantadas no Brasil, desde a sua colonização até os dias atuais, formou-se uma mentalidade específica acerca do ensino e da educação. Com isto, é possível encontrar o nascimento da mentalidade em torno do ensino e da educação que pode ser visualizado no Brasil atualmente, desde o processo das revoluções burguesas do século XIX. Por essas revoluções, a burguesia assume o controle político dos Estados e coloca todas as suas instituições a seu serviço. Com as escolas e a educação não seria diferente.

A afirmação desse projeto burguês de educação no espaço europeu, que levou à organização dos sistemas nacionais de ensino e que a fez ser um "[...] direito de todos e dever 


\section{Revista HIISTEYIDIR On-line}

do Estado" (SAVIANI, 2006, p. 5), teve como principal objetivo promover a construção de uma sociedade que consolidasse a existência da democracia burguesa, implantada pelo processo revolucionário. Transformar os súditos do Antigo Regime em cidadãos seria o primeiro passo para se superar o problema da marginalidade causado pela ignorância em que se encontrava grande parte das populações. Cabia à educação a transmissão do conhecimento que havia sido acumulado pela humanidade até esse momento. Como o que estava em jogo aqui era a transmissão do conhecimento, os alunos possuíam um papel secundário no ensino. Apenas deveriam dirigir-se às classes, organizadas em fileiras e carteiras, e ouvir aquilo que o professor, grande protagonista desse modelo de ensino, transmitia.

O fracasso desse ideal de projeto educacional não demorou a acontecer. Nem toda a população conseguia ingressar nas escolas e nelas permanecer. E nem todos aqueles que nelas permaneciam conseguiam se adequar ao modelo de sociedade implantado. Este modelo intitulado de Escola Tradicional recebeu severas críticas e mostrou a necessidade de reforma.

É nesse processo de críticas que se desenvolveu a Escola Nova. O marginalizado deixava de ser o ignorante e passava a ser o rejeitado. A educação passou a privilegiar os aspectos psicológicos do estudante, deslocando-se do eixo do modelo anterior, que estava centrado no professor, para os alunos e o seu processo de aprendizagem:

[...] O professor agiria como um estimulador e orientador da aprendizagem cuja iniciativa principal caberia aos próprios alunos. Tal aprendizagem seria uma decorrência espontânea do ambiente estimulante e da relação viva que se estabelece entre os alunos e entre estes e o professor. (SAVIANI, 2006, p. 9).

A implementação do Escolanovismo, em substituição da Escola Tradicional, aparece em nosso país no contexto da eclosão da Revolução de 1930, a revolução burguesa brasileira. Através dela, há ruptura com as estruturas agrárias que dominavam a sociedade até então e confere-se a essa classe social qual o domínio político e econômico do país. O Estado brasileiro se organiza como outrora ocorrera na Europa, de modo a atender aos interesses da burguesia, iniciando o processo de industrialização do país. Nesse primeiro ciclo, com a construção das indústrias de base:

[...] se o que se resultou politicamente da Revolução de 1930 foi um "Estado de Compromisso", caberia considerar que esse Estado se pôs como agente, no plano governamental, da hegemonia da burguesia industrial. Não importa se isso foi, ou não resultado, de uma diretriz política deliberadamente formulada e intencionalmente conduzida. (SAVIANI, 2008b, p. 193).

A criação do Ministério da Educação e da Saúde Pública, em 1931, já revelou a preocupação do governo provisório de Getúlio Vargas em tratar as questões educacionais no âmbito nacional. Firmou-se um projeto de educação que articulou o trabalho no processo de instrução técnico-profissional e o desenvolvimento da psicologia infantil. Começam a ganhar corpo e se fortalecer em nosso país, portanto, os ideais escolanovistas, que influenciaram as práticas adotadas pelos sistemas de ensino nos anos subsequentes.

No entanto, com a implantação das indústrias de bens de consumo no Brasil na década de 1950 e consequentemente com a necessidade de formação de mão de obra 
qualificada para o trabalho nessas fábricas, começaram a serem implantadas novas propostas para a educação. Surge uma escola tecnicista, que procurou implementar no âmbito educacional os mecanismos que orientavam o trabalho das fábricas, que passaram a determinar o processo educacional, para facilitar ao aluno integrar-se ao mercado de trabalho e ainda manter a classe trabalhadora sobre controle, fornecendo a ela, segundo Saviani (2013), uma educação limitada e parcial.

A substituição do tecnicismo para a visão mercadológica da educação, a partir da década 1990, fundamentada nos ideais neoliberais e materializada nas propostas curriculares, nas legislações e nas políticas em toda a educação nacional, não alterou este quadro. Adotaram-se como princípios a flexibilização, a diversificação do trabalho pedagógico e a constante avaliação do desempenho escolar, como meios de garantir a qualidade dos sistemas de ensino, mas que acabam por produzir o mesmo ensino fragmentado, dissociado dos interesses daqueles que frequentam o espaço das escolas.

Em oposição a esses modelos, surge no Brasil a Pedagogia Freiriana, cujo grande objetivo, é promover uma educação que privilegie as camadas populares. Rompendo com o modelo daquilo que Freire (2005) denominou educação bancária, que via o aluno como um ser vazio, e que nele o professor poderia "depositar" os conteúdos, propõe o desenvolvimento de uma prática pedagógica que desperte nos estudantes a consciência crítica de sua realidade política, econômica e social, que acabe por conduzir a uma Educação como Prática para a Liberdade. Essas ideais compuseram importante elemento nas teorias da educação em anos subsequentes.

No entanto, a opção política do Estado brasileiro consiste em não oferecer uma educação cultural integral a toda população, a ordem burguesa se consolidou no currículo da educação brasileira, através do processo constante de alienação. Não é dada ao explorado a oportunidade de conhecer a sua exploração, pois o processo de alienação se dá através da recusa do Estado em oferecer uma educação não alienada. As camadas populares acreditam vivenciar de fato a experiência democrática, aceitam o sistema e permanecem presas a essa carga ideológica, "[...] dominador não se liberta se ele não vier a dominar o que os dominantes dominam. Então dominar o que os dominantes dominam é condição de libertação". (SAVIANI, 2006, p. 55).

A partir do desenvolvimento dessas ideias, e da afirmação da burguesia enquanto detentora do poder político no Brasil, a educação passou a ser vista como um investimento ligado à produção material, pois através dela os recursos humanos seriam qualificados e levariam a um rápido crescimento econômico. O que podemos visualizar desse processo é que a educação foi posta a serviço do Estado burguês, para aumentar os ganhos e consolidar o seu domínio ideológico sobre as demais classes sociais, através da recusa em fornecer aos grupos dominados uma formação educacional que privilegie os reais anseios da sociedade em que se desenvolve.

A implantação e o desenvolvimento da democracia burguesa no Brasil acabaram por determinar as estruturas que regem os comportamentos que se evidenciam na sociedade, o que favorece a formação de uma mentalidade específica acerca do ensino em geral, e aqui do ensino de História no que diz respeito ao período medieval. Percebe-se que todas essas ideias pedagógicas, apontadas anteriormente, coexistem no inconsciente coletivo, alguns princípios de forma mais forte, outros de forma mais superficial, mas que contribuem para a 


\section{Revista HIIST'TEIDBR On-line}

Artigo

doi: $10.20396 /$ rho.v17i4.8645888

formação de uma dada visão para todos aqueles que, de alguma forma, estão envolvidos no processo educativo.

Este inconsciente coletivo reforça a ideia de Le Goff (2008) sobre as mentalidades que correspondem a um conceito que muito fora explorado na historiografia a partir do desenvolvimento da Nova História, pois se associa às novas temáticas que essa corrente trouxe para o domínio da história. A ideia das mentalidades se aproxima da antropologia e da sociologia, quando procura buscar o que um ser humano, em especial, tem em comum com os demais de seu tempo. Ou seja, é uma história que busca dar conta da coletividade. Portanto, podemos incluir a história das mentalidades no âmbito da história estrutural, pois esta também constitui um dos mecanismos de organização das sociedades.

Lidar com essa história é se preocupar com os comportamentos e com as atitudes de um povo diante de um determinado fenômeno. É estar disposto a se embrenhar na leitura de quaisquer documentos que contribuam para levar ao pensamento de uma sociedade. Formas de agir que se manifestam de forma automática, inconsciente, levando o historiador a se defrontar com outros pontos de interesse:

A história das mentalidades obriga o historiador a interessar-se mais de perto por
alguns fenômenos essenciais de seu domínio: as heranças, das quais o estudo
ensina à continuidade, as perdas, as rupturas [...]; a tradição, isto é, as maneiras
pelas quais se produzem mentalmente as sociedades, as defasagens, produto de
retardamento dos espíritos em se adaptarem às mudanças e da inegável rapidez
com que evoluem os diferentes setores da história. Campo de análise privilegiado
pela a crítica das concepções lineares a serviço histórico. (LE GOFF, 1995, p. 72).

Em um determinado período, podem coexistir diferentes mentalidades. A origem de uma nova maneira de interpretar o mundo não significa que aquelas que outrora determinaram o pensamento foram superadas. Elas coexistem e acabam por se completar. Por isso, só podem ser entendidas em um nível coletivo e estar associadas "[...] à história dos sistemas culturais, sistemas de crenças e valores, de equipamento intelectual no seio dos quais as mentalidades são elaboradas, viveram e evoluíram”. (LE GOFF, 1995, p. 78).

Consciente desta relação entre as mentalidades e o meio em que elas se desenvolveram, é compreensível a importância dada neste estudo aos contextos de produção das ideias pedagógicas, segundo Saviani (2008b). Houve a necessidade, para discussão de modo geral associar à ascensão dos ideais neoliberais no espaço mundial para compreender a criação das propostas curriculares oficiais, cuja análise foi tratada no segundo momento deste estudo. Mostramos a constituição das ideias nos séculos XIX e XX, para compreendermos a constituição das mentalidades sobre o ensino no Brasil.

$\mathrm{E}$, com os dados da pesquisa empírica observa, que princípios ligados à educação tradicional, ao escolanovismo, ao tecnicismo e ao neoliberalismo acabam por coexistir nas mentalidades acerca do ensino. Esse fato resulta em um conflito, pois essas diferentes visões atribuem uma dada funcionalidade para a educação que, nesse processo confuso da coexistência de diferentes ideais, acaba por se perder de vista o papel da atividade educativa para as sociedades. É mudanças como as políticas públicas, o sistema de avaliação, a presença do Estado, que vêm de fora das escolas para serem implantadas de acordo com necessidades que lhes são externas. 


\section{Revista HIIST'TEIDBR On-line}

Artigo

doi: $10.20396 /$ rho.v17i4.8645888

Ainda é possível perceber a força dos princípios ligados ao modelo de educação tradicional no inconsciente coletivo dos professores e na própria organização do espaço das salas de aula. O professor aparece enquanto detentor do saber e os alunos como sujeitos passivos no processo de ensino e aprendizagem, apenas tomando nota de todas as informações passadas em aula, para reproduzi-las no contexto das avaliações.

No entanto, essa descrição não condiz com as determinações curriculares oficiais que pedem um ensino associado a aspectos do mundo globalizado, como a tecnologia e a preparação do aluno para o mundo do trabalho. O que se percebe, portanto são, a existência de práticas que estão ligadas, em sua maioria, à Escola Tradicional e uma forma de organização dos sistemas de ensino, relacionada a outras concepções.

Uma das convenções que constituem a mentalidade das comunidades acerca do ensino é que em educação as mudanças encontram resistência para se operar. Tomando por base a existência dessas estruturas que dirigem e controlam o inconsciente coletivo acerca do ensino, é compreensível a resistência da comunidade escolar que muitas vezes as considera supérfluas, diante dos reais propósitos para a execução do ensino.

Aqui reside a necessidade de se manter um ensino de história ainda ligado à memorização e à reprodução dos fatos, que não leve à compreensão crítica da sociedade, e à manutenção do medievo, no lugar das trevas. Mudar significaria desestabilizar as verdades já consolidadas. Mesmo que a historiografia caminhe a passos largos e que os documentos curriculares permitam aproximar a história escolar da história acadêmica, isso acaba por ser feito de modo superficial, não promovendo mudanças na prática da história escolar.

\section{DA COLETA DE DADOS À ANÁLISE DA PESQUISA EMPÍRICA}

A pesquisa empírica consistiu na aplicação de questionários com questões semiestruturadas a vinte e cinco professores de história da rede escolar de Pouso Alegre, interior do estado de Minas Gerais, no período dos meses de novembro a dezembro de 2013 e de fevereiro a maio de 2014. Para isso, foi solicitada a autorização dos gestores escolares, em concordância com a supervisão pedagógica ${ }^{5}$, para que os professores de história pudessem ser os participantes respondentes dos questionários. Foram realizadas durante as reuniões pedagógicas que acontecem semanalmente, após uma explicação do estudo em questão, da importância de sua participação neste trabalho de pesquisa e da apresentação do Termo de Consentimento Livre Esclarecido (TCLE), para que assim os questionários fossem entregues para o preenchimento pelos docentes.

Os professores participantes dessa pesquisa fazem parte das redes municipal, estadual e particular e atuam no Ensino Fundamental II. A escolha por representantes das três diferentes redes de ensino justifica-se pela necessidade de analisar como o impacto das diferentes ideias pedagógicas se reflete no ensino da Idade Média no Ensino Fundamental e como são apropriadas no momento de forjar uma prática de ensino diferenciada.

Através do questionário buscou-se conhecer o perfil profissional dos docentes, para compreender sua formação no intuito de analisar as práticas de ensino por eles adotadas. Segundo Guimarães (2003), a visualização dessa formação e das condições de trabalho é imprescindível para o entendimento da prática desenvolvida em sala de aula. 


\section{Revista HIIST'TEIDBR On-line}

Nesta primeira etapa, os dados foram compilados e organizados em tabelas, para facilitar a visualização e comparação das práticas adotadas com o período de formação dos professores. A tabela I abaixo apresenta dados relativos à formação dos professores, tanto em seu momento inicial, quanto na formação continuada. Buscaram-se os dados relativos à sua graduação e pós-graduação e se existe formação continuada. Na tabela II, apresentaramse os dados profissionais dos participantes, revelando a sua situação funcional, o tempo de docência, o tempo na unidade escolar, à modalidade de ensino que atuam e a rede em que trabalham.

Os participantes da pesquisa foram identificados como P1, P2... P25 para garantir questões éticas que envolvem a pesquisa em Educação e também em cumprimento ao protocolo do projeto desta pesquisa realizado no Comitê de Ética - CEP de Humanas ${ }^{6}$.

Quanto ao perfil da formação dos participantes da pesquisa do total de vinte e cinco (25), todos possuem graduação em História e apenas um (1) com formação além de História no magistério de nível médio. Perguntados se são pós-graduados, quatorze (14) possuem especialização e um (1) possui mestrado.

Percebeu-se também quanto ao período de formação que o participante com mais tempo de formação data do ano de 1991 dois (2) e mais recente de 2013 um (1), a maioria se encontram dentro deste período (1991-2013). Questionados sobre a formação continuada, se recebem da rede ou não, dezenove (19) afirmaram que não, seis (6) afirmaram que sim.

Esse levantamento de dados sobre os professores cumpriu o papel de retratar quem são e qual a formação os docentes de História da rede possuem. Assim sendo, foram criadas possibilidades de análise e das categorias construídas na segunda e terceira parte do questionário, constituídas de questões abertas, que possibilitaram uma liberdade de expressão do participante em descrever a sua prática de ensino de história.

Foi questionado aos participantes sobre sua situação funcional na rede pública e privada. Do total apenas dois trabalham somente na rede particular os demais são da rede pública municipal e estadual. Dado esse que retrata bem como as fontes históricas são abordadas no ensino de História na rede pública de Pouso Alegre/MG. Quanto a modalidade de ensino que atuam vinte (20) afirmaram Ensino Fundamental II ( $6^{\circ}$ ao $9^{\circ}$ ano) e Ensino Médio e somente cinco (5) somente no Ensino Médio.

Outro dado levantando com significado que interfere no uso das fontes históricas no ensino de História foi quando perguntados sobre sua situação funcional, se efetivo ou designado na rede pública, dos vinte e três (23), um a mais que a metade, catorze (14) são efetivos, treze (13) são designados, o que no entendimento dessa pesquisa é um dado complicador para qualidade do trabalho na disciplina, pois significa que há de tempos em tempos professores novos na escola. Pois, essa é a realidade dos designados a cada ano letivo, nem sempre permanecem na mesma escola.

Na segunda parte do questionário, foram coletados dados que permitiram conhecer a relação que os professores estabelecem com os PCNs e o CBC/MG e se há o trabalho com fontes históricas em suas aulas. Procurou-se compreender se este emprego foi por mera determinação da documentação curricular oficial ou se os participantes consideram as fontes como importantes recursos para o desenvolvimento da aprendizagem em história. 
Através da análise das respostas, foi possível visualizar aspectos relativos àquilo que conduz e constrói a prática dos professores e sua mentalidade acerca do ensino de história e sobre a Idade Média. Através da difusão dessa mentalidade, conceitos relativos ao ensino são reproduzidos ao longo da história e passam a compor o imaginário coletivo das sociedades.

Estas questões ainda possibilitaram perceber as relações que os docentes possuem com as orientações dadas pela documentação curricular oficial, resistindo ou reproduzindo seus desígnios e assim compondo a dinâmica da história no espaço de sala de aula. Le Goff (2006) compara o ofício do professor ao do pianista que, através da leitura e da execução daquilo que consta nas partituras, confere vida a sua obra. O professor de história, em contato com esse universo de informações que perpassa cotidianamente a sua prática, dá vida à história. Uma história própria, diferenciada, que se constrói a partir do contato com a dinâmica escolar.

\section{FONTES HISTÓRICAS E A CONSTRUÇÃO DE VISÕES SOBRE O ENSINO DA IDADE MÉDIA}

Trabalhou-se com as análises realizadas nas partes B do questionário aplicado aos vinte e cinco (25) professores, participantes da pesquisa. Foram construídas categorias de análises a partir das respostas de cada questão que compunham estas partes do questionário aplicado. Esta categorização teve por finalidade averiguar as práticas de ensino de História no uso das fontes e da abordagem dada à Idade Média.

Os aspectos analisados nas construções dessas categorias permitiram conhecer, descrever, compreender e problematizar a prática de ensino, os conteúdos elencados e a forma de apropriação desses conteúdos pelo ensino de História no Ensino Fundamental. De acordo com Guimarães (2003), a trajetória do professor de história se constitui na coletividade deste profissional com seus pares, configurando a sua prática docente aos traços de luta e de resistência.

As dezesseis questões (fechadas e abertas) da Parte B do questionário objetivaram conhecer como os professores se apropriam das fontes históricas como recurso didático durante o desenvolvimento dos conteúdos em sala de aula, e também como elas contribuem para o desenvolvimento do ensino acerca do período medieval. Foram pontuadas, de acordo com cada questão, categorias que possibilitam conhecer melhor a realidade do uso destas fontes.

\section{$1^{\text {a }}$ CATEGORIA: O CURRÍCULO ENQUANTO DIRETRIZ NORTEADORA}

As duas primeiras questões da Parte $\mathrm{B}$ do questionário procuraram investigar a relação que os docentes estabeleciam com a documentação curricular oficial do Estado e como ela influencia a prática de ensino no universo de sala de aula, desenvolvida pelos professores. Influência esta que de modo indireto contribui para edificar uma dada visão sobre a Educação e o ensino de história, como foi problematizado a seguir. 


\section{Revista HIIST'TEIDBR On-line}

Primeiramente, foram apresentados os dados coletados, em seguida, as problematizações realizadas do confronto com as opiniões dos participantes do estudo com a perspectiva teórica adotada. Durante o processo de análise e compilação dos dados, foi possível organizar em sete grupos diferentes as expressões que apareciam com maior frequência nas respostas dadas às questões. Embora não tenham sido as mesmas, destaca-se o papel do currículo enquanto aquilo que orienta e norteia a prática docente, mostrando a influência direta existente entre as orientações oriundas desses documentos nas ações desenvolvidas pelos professores em sala de aula.

De acordo com Saviani (2008b), ao longo da história da educação brasileira, todas as reformas que afetaram o trabalho do professor dentro da sala de aula foram pensadas fora da escola por aqueles que indiretamente estavam envolvidos no dia-a-dia escolar. Isso fez com que as necessidades da escola nunca fossem levadas em conta no processo da formação curricular e na constituição das políticas públicas para a Educação.

Ao professor e a todos aqueles que atuam no espaço escolar cabiam apenas seguir aos desígnios externos, enquanto um norte, uma diretriz, aquilo que viera para orientar e conduzir a prática de ensino. Refletir sobre o currículo, analisá-lo e questioná-lo não constitui um hábito para os profissionais que atuam na Educação Básica, que forjaram sua mentalidade de modo externo a esse processo e, que por este fato, enxergaram o currículo apenas como algo a ser seguido, sem a necessidade de se levantar quaisquer questionamentos a cerca dele. Quatro dos participantes apontaram o currículo enquanto algo que norteia e orienta o ensino, refletindo a relação descrita acima:

(P9): Para a orientação do professor na sala de aula.

(P14): É utilizado como um norteador no currículo básico complementando o conteúdo.

(P15): Os documentos são responsáveis por orientar o ensino de história no que se refere aos temas que serão trabalhados durante o Ensino Fundamental.

(P20): Orientam o ensino.

Estas retratam o reflexo do contato com a própria documentação que se descreve como algo encarregado de orientar a Educação Nacional, no caso dos PCNs, segundo Brasil (1998), ou no caso do CBC, na educação mineira. Ambas constituídas por realidades culturais e humanas múltiplas, cuja busca por contemplá-las teria sido o grande objetivo da documentação. Por isso, Guimarães (2003) aponta como grande característica da constituição desses documentos o multiculturalismo.

Percebe-se a partir destas respostas obtidas que a formação do professor de História não está atrelada ao desenvolvimento de uma postura que o leve a questionar os desígnios externos que afetam as escolas e interferem no desenvolvimento de sua prática de ensino. Assim, desprovidos de criticidade os professores tomam o currículo como algo a ser seguido sem questionamentos, e que atua de modo a conduzir as ações desenvolvidas em sala de aula. O caráter unificador desses documentos, também descrito em seus textos, é salientado:

(P18): Regimentar e unificar as propostas de ensino em todo país e no estado mineiro, respectivamente. 


\section{Revista HIIST'TEIDBR On-line}

(P20): São documentos que regem os sistemas de ensino e contribuem para a construção dos materiais didáticos, planos de ensino e metodologias.

As mentalidades, para Le Goff (1995), são constituídas em grupo, ao longo dos séculos. Por isso, é possível compreender o padrão da maioria das respostas dos docentes com relação a essa questão, não sendo surpresa a visão que os professores tem do papel dos PCNs e do CBC. Guimarães (2003) salienta que a constituição profissional do professor se dá através do contato com a documentação proveniente de fora das escolas, com outros membros da sua categoria profissional, com as diferentes fases da sua formação (inicial e continuada), entre outros aspectos. Tudo isso acaba por constituir as mentalidades do professor de história, que tem uma forma particular de tratar a Educação, sua disciplina e as metodologias possíveis para ensiná-la. Em meio às particularidades que existem em cada resposta do questionário, sobrepõem-se os traços comuns, as provas da existência, do que Le Goff (1995) denomina como inconsciente coletivo, constituído ao longo dos séculos e que ainda influi na percepção do mundo de todo um grupo de pessoas.

No entanto, essas particularidades constituem outro importante ponto de reflexão. A colocação de (P14) que chama a atenção pelo fato de considerar o currículo enquanto algo que apenas complementa o conteúdo, ou seja, esse participante considera as temáticas históricas, a serem tratadas no Ensino Fundamental, como algo superior à documentação oficial:

(P14): É utilizado como um norteador no currículo básico complementando o conteúdo”.

Essa visão, segundo Bittencourt (2009), é fruto do caráter conteudista que predominou durante muitos anos no ensino de história, herança da influência positivista na composição dessa disciplina escolar. Para esse método de produção historiográfica, os fatos deviam ser descritos de acordo com a documentação levantada pelo historiador, sem reflexões. A fonte histórica era considerada um instrumento da verdade e, por isso, sem a necessidade de enfrentar qualquer tipo de questionamento.

Introduzido nas escolas de primeiras letras, ainda no período imperial da história brasileira, o ensino de história era utilizado como um meio de desenvolver nos alunos as habilidades de leitura e os valores patrióticos, ao tratar em seus temas os heróis nacionais. Os fatos históricos se sobrepunham a quaisquer reflexões sobre eles. Tratavam apenas da verdade e não havia necessidade de questionar a verdade. Desse modo, os conteúdos se sobrepõem ao currículo, que aparece para (P14) com uma função complementar, além da dirigente, apontada pelos demais participantes do estudo.

(P12) mencionou divergências existentes entre os conteúdos apontados pelos PCNs e o CBC. Essas divergências são fruto dos próprios objetivos que constituem cada um dos documentos. Enquanto o primeiro possui uma abrangência nacional, o segundo está relacionado à educação mineira:

(P12): Os PCNs são importantes, pois tem a proposta de unificar e guiar o ensino em âmbito nacional. Já o CBC propõe conteúdos não condizentes com o PCN”. 
Apenas alguns conteúdos do CBC não são condizentes aos PCNs. Como foi apontado pela análise, não há divergências no que diz respeito aos objetivos dos dois documentos, mostrando que a finalidade para o ensino de história é a mesma, ou seja, a formação da cidadania e o preparo para a vivência democrática. Isso se manifesta no processo de seleção dos conteúdos, que acabam por reunir temas comuns.

Esta condição permite pouca reflexão sobre o currículo e demonstra que os professores possuem pouca consciência sobre sua função, o que torna inviável a execução daquilo que os PCNs trazem em sua introdução:

\begin{abstract}
Os Parâmetros Curriculares Nacionais reconhecem a realidade brasileira como diversa, e as problemáticas educacionais das escolas, das localidades e das regiões como múltiplas. É no dia-a-dia das escolas e das salas de aulas, a partir das condições, contradições e recursos inerentes à realidade local e educacional, que são construídos os currículos reais. São grupos de professores e alunos, de pais e educadores, em contextos sociais e educacionais concretos e peculiares, que formulam e colocam em prática as propostas de ensino. Estes parâmetros oferecem mais um instrumento de trabalho para o cotidiano escolar. (BRASIL, 1998, p. 15).
\end{abstract}

Quanto à educação privada, um aspecto se sobressai. A adoção de apostilas enquanto material didático e a pressão oriunda dos coordenadores e pais de alunos em que se dê conta de cumprir o conteúdo da mesma, fazem com que os docentes encarem a apostila enquanto única estratégia de ensino a ser seguida. Não constitui como prática questionar o material adotado pela escola, apenas segui-lo, residindo aqui à ideia de que a garantia de uma qualidade a ser alcançada está focada no seu bom uso.

$\mathrm{O}$ aspecto que mais sobressaiu sobre o uso das apostilas reside em ser aquilo que supre a necessidade do professor em ter algo que conduz sua prática, eximindo-o de maiores preocupações no preparo de suas aulas, em organizar atividades diversas de um mesmo conteúdo ou até de deixar que seus alunos criem soluções para as questões. Seja na educação pública, com a documentação curricular oficial, seja na educação privada, com as apostilas, o professor quase sempre aponta para necessidade de algo para orientá-lo, norteá-lo, fruto do direcionamento à que sempre esteve submetido o ensino.

(P3): Na minha prática pouco impacto, pois na rede particular predominam-se as apostilas".

Quando questionados se existia o impacto dos documentos na prática docente desenvolvida pelos professores, foi constada a seguinte situação. Dos vinte e cinco (25) participantes, vinte e quatro (24) alegaram que sua prática estava influenciada de algum modo pela documentação. Apenas um (1) participante alegou que não estaria influenciado por ela, uma vez que atua na rede privada e que ali a grande influência era proveniente do material apostilado.

Mais uma vez, o papel direcionador do currículo aparece evidenciado na fala dos participantes, através de palavras como determinam, constroem os planejamentos, orienta e formulam, refletindo a construção de uma prática alienada e que acaba por ser colocada a serviço dos interesses do Estado. 
Para Saviani (2006), a libertação da sociedade de seu estágio de alienação só será possível a partir da aquisição de conhecimentos dominados por aquela parcela ínfima da população, que desfruta de uma situação de privilégio frente aos demais. Enquanto o ensino estiver submetido apenas aos interesses do Estado, que atua na manutenção dos privilégios desses grupos, este quadro tende a se manter e a prática continuará sendo desprovida de sentido.

Quando se trata do ensino de História, percebemos que esta prática tende à manutenção do seu caráter reprodutivista de informações consolidadas historicamente, sob a falácia do desenvolvimento da cidadania e da experiência democrática, quando na verdade tende apenas à preparação do aluno para ingressar nesse mundo capitalista, como apenas mais um elemento do sistema que o reproduz, o admira, e que se tornou incapaz de transformá-lo.

\section{$2^{\text {a }}$ CATEGORIA: FONTES HISTÓRICAS COMO INSTRUMENTO DE ALIENAÇÃO}

As demais questões que compõem a Parte B do questionário se encarregaram de averiguar a relação estabelecida pelos participantes do estudo com as fontes históricas, enquanto um meio de efetivação do processo de ensino-aprendizagem. Muito tem se falado a respeito de novas metodologias para o ensino de História: a recente produção historiográfica, documentos oficiais provenientes dos departamentos governamentais, e a produção didática adotada pelas instituições de ensino. Todas convergem para um mesmo ponto quando determinam a incorporação das fontes históricas nos trabalhos realizados em sala de aula.

Pesquisadores e pesquisadoras reconhecidos do ensino de História de diversas universidades brasileiras atuais, como Circe Maria Fernandes Bittencourt (USP), Carla Bassanezi Pinsk (UNICAMP), Leandro Karnal (IFCH/Unicamp), Selva Guimarães (UFU) e Nilton Mullet Pereira (UFRGS) afirmam que esses documentos propiciam o desenvolvimento de situações de ensino e aprendizagem que favoreçam o desenvolvimento dos conteúdos, que possibilitarão aos alunos desempenharem com propriedade e consciência o sua função social.

Vinte e um (21) participantes do estudo afirmaram perceber nos documentos uma exigência quanto ao uso das fontes históricas em suas aulas, acompanhando essa tendência metodológica no que diz respeito ao ensino de História. Alegaram, em sua maioria, que a utilização dos documentos, para o PCNs e o CBC/MG, diversifica as aulas e contribuem para o desenvolvimento de metodologias válidas para ensinar os conteúdos:

(P1): No CBC elas aprecem atreladas aos temas e aos eixos temáticos.

(P10): Elas são apontadas como caminhos possíveis para se ensinar História.

(P20): Os documentos colocam as fontes como recursos para se ensino História.

No entanto, dois (2) dos participantes não encontram exigência alguma no que diz respeito a essa temática. Um alega desconhecimento com relação à documentação curricular oficial, pois esta não influiria em sua prática. Outro menciona que os documentos apenas 
apontam o desenvolvimento de competências e habilidades, não contendo nenhuma indicação metodológica:

(P2): Não tenho acesso aos documentos, pois não influenciam a minha prática. (P11): Não. Apresenta o "desenvolvimento" de competências e habilidades. Absurdamente como desenvolvimento burocrático.

Para outros, no entanto, seria possível constatar que as fontes históricas são associadas apenas a alguns temas, não havendo nenhuma exigência a respeito de sua utilização:

(P7): Ainda é pequena, mas já tem a indicação do uso de fontes históricas como ferramenta para desenvolver as habilidades em alguns tópicos, principalmente no Ensino Médio. No CBC do Ensino Fundamental é menor essa sugestão.

(P21): Existe em alguns conteúdos a menção do uso de fontes históricas, porém, não em todo o processo.

A existência de uma maioria percebendo a exigência da documentação curricular acerca das fontes históricas revela que a formação inicial e continuada tem se preocupado em incluí-las enquanto recursos para se ensinar História. No entanto, a desconsideração de alguns frente às orientações metodológicas dos PCNs e do $\mathrm{CBC}$ revela que os documentos curriculares e as metodologias por eles apresentadas ainda não foram incorporados por todos os docentes, ou ainda, que no desconhecimento das exigências, uma prática de ensino independente esteja sendo consolidada.

Este fato chama a atenção, pois todos os participantes, ou seja, os que reconhecem e os que não reconhecem a exigência nos $\mathrm{PCNs}$ e $\mathrm{CBC} / \mathrm{MG}$ a respeito dessa metodologia, relataram que utilizam as fontes históricas em suas aulas, principalmente porque percebem a importância desses recursos enquanto um meio de desenvolver as temáticas a serem tratadas nas aulas.

É demonstrada a percepção de que as fontes trazem para o espaço da sala de aula uma variação, seja na organização da aula em si ou na forma de abordar os temas. Para Le Goff (1990), esse fato é fruto da relação que o historiador constrói junto à documentação por ele utilizada. É na leitura e interpretação da documentação, associadas à visão de mundo que este profissional detém que as temáticas históricas ganham vida e são passíveis de análise, que tende a ser uma análise particular para cada historiador, uma vez que ela é influenciada por sua própria vivência.

(P5): Geram contrapontos da bibliografia social ou a oficial. (P23): Elas contribuem para diversificar as aulas".

Outro aspecto que ressalta desse fato advém dos discursos que permeiam a educação. Sempre é mencionada ao professor a necessidade de reconstruir a sua prática, adaptá-la aos interesses dos alunos de seu tempo. Exigência esta que passou a ser, segundo Saviani (2006), inclusa no ensino a partir da introdução dos ideais escolanovistas no Brasil, ainda na primeira metade do século vinte.

Ao longo das décadas, os profissionais da educação aderiram a este discurso e passaram e incluí-lo para descrever a sua prática ou as ferramentas por eles utilizadas. 


\section{Revista HIISTEYIDIR On-line}

Quando questionados a esse respeito, os participantes trazem a tona um discurso que permeia cotidianamente o seu exercício profissional, assim como também as falas que ouviam enquanto aluno de graduação e até mesmo na Educação Básica. Convencionou-se que ser professor é estar em busca do novo, daquilo que desperta o interesse do aluno para a sua disciplina e que seja capaz de tornar as aulas mais atrativas e dinâmicas. Este fato passou também a compor as mentalidades acerca do ensino e da profissão docente.

Além da variação dos temas e das aulas, também foi apontado como justificativa o fato das fontes estarem presentes no material didático (06 participantes), ou ainda que, estavam seguindo a tendência atual para o ensino de História (4 participantes). Apenas um (1) participante não respondeu a essa questão.

Foram questionados também, sobre quais seriam as fontes históricas dominantes durante as aulas e também o porquê de sua escolha. A maioria dos participantes apontou que utiliza as fontes escritas e visuais em suas aulas. Ao relacionarmos os dados, percebe-se que são apontadas como fontes capazes de despertar o interesse dos alunos e que ainda são mais facilmente encontradas ou reproduzidas no espaço escolar. Presentes no material didático adotado e na internet, essas fontes são de fato um elemento comum no ensino de História. Para Saliba (2010), não podemos desprezar o potencial da imagem, enquanto recurso válido para o ensino. Os alunos pertencem a um contexto histórico em que o peso da imagem é extremamente relevante e saber se apropriar dessa tipologia de fontes históricas é conferir ao ensino de História uma relevância aos olhos daqueles que se dedicam a seu estudo:

(P5): Observar os interesses quando se veicula imagem, movimento. Novas gerações são ansiosas por imagem e som.

(P13): As imagens muitas vezes retratam ainda outras fontes, mesmo que de uma forma indireta.

(P21): Através da imagem o cognitivo do aluno é despertado de forma mais eficiente.

Os participantes apontaram que utilizavam as fontes históricas, pois se encarregavam de variar as aulas e conferir aos temas novas abordagens. Mas, quando questionados sobre o porquê da escolha de determinada fonte em detrimento de outras, as respostas convergiam para o interesse dos alunos e para a facilidade na reprodução desses documentos. Apenas três (3) participantes continuaram a alegar que as fontes históricas propiciam aos temas abordagens que fogem daquelas convencionais.

Estes dados demonstram que as fontes históricas estão incorporadas ao discurso docente, mas de modo acrítico, pouco reflexivo, tal qual aparecem nos documentos curriculares oficiais, constituindo parte da alocução a respeito das mudanças no ensino de História. As fontes passam a pertencer à prática, não como um meio de suscitar novas abordagens, mas como um meio de reafirmar a memória oficial já presente nos livros didáticos.

Bittencourt (2009) salienta que este trato acrítico aos documentos faz com que os professores percam a possibilidade de renovação das temáticas históricas, mantendo o ensino dessa disciplina no seu mesmo lugar comum. Esse fato é fruto da relação já descrita anteriormente, em que as escolas sempre foram encaradas não como um ambiente de 
construção de suas próprias pedagógicas, mas sim como um lugar de execução das práticas pensadas fora dessa instituição. Desse modo, as falas provenientes dessa documentação acabam por fazer parte das mentalidades do ensino.

Além disso, a desvalorização histórica do magistério fez com que esses profissionais sempre possuíssem longas jornadas de trabalho, o que acabou por não propiciar o estudo e a adoção de postura crítica frente aos desígnios externos e a sua própria prática. O que para Guimarães (2003), leva à constituição de uma classe profissional e a formação da mentalidade comum ao professor de História com seus pares.

Desse modo, as fontes históricas não aparecem como recursos destinados a promover um novo ensino de História, que desperte no aluno o espírito questionador frente às realidades já consolidadas. As fontes são tratadas apenas como metodologias que tendem a reproduzir o caráter alienante em que se encontra o ensino. Em consonância com a documentação curricular oficial, a prática de ensino em História reproduz a mesma visão de mundo, verdades construídas por aqueles que sempre detiveram o poder.

\section{REFERÊNCIAS}

BITTENCOURT, Circe Maria Fernandes. Ensino de história: fundamentos e métodos. São Paulo: Cortez, 2009.

BRASIL. Currículo Básico Comum (CBC) - história. SEE/MG, 2007.

BRASIL. Parâmetros curriculares nacionais: história, geografia. Secretaria de Educação Fundamental. Brasília: MEC/SEF, 1998.

FREIRE, Paulo. Pedagogia do oprimido. São Paulo, SP: Paz e Terra, 2005.

GUIMARÃES, Selva. Didática e prática de ensino em história. Campinas, SP: Papirus, 2003.

LE GOFF, Jacques (Org.). A História nova. São Paulo: Martins Fontes, 1998.

LE GOFF, Jacques. As mentalidades: uma história ambígua. In: LE GOFF, Jacques. NORA, Pierre. (Org.). História: novos objetos. Rio de Janeiro: Francisco Alves, 1995. p. 68-83.

LE GOFF, Jacques. Em busca da Idade Média. Rio de Janeiro: Civilização Brasileira, 2006.

LE GOFF, Jacques. História e memória. Campinas, SP: Editora da Unicamp, 1990.

LE GOFF, Jacques. Uma longa Idade Média. Rio de Janeiro: Civilização Brasileira, 2008.

RIBEIRO, Álvaro Nonato Franco. Fontes históricas e ensino de história: olhares sobre o Medievo. Dissertação (Mestrado em Educação) - Universidade do Vale do Sapucaí, Pouso 
Alegre, MG, 2014. Disponível em: <http://www.univas.edu.br/me/docs/dissertacoes2/7. pdf.>. Acesso em: 30 mar. 2016.

SALIBA, Elias Thomé. Experiências e representações sociais: reflexões sobre o uso e consumo de imagens. In: BITTENCOURT, Circe (Org.). História na sala de aula. São Paulo: Contexto, 2010. p. 87-118.

SAVIANI, Dermeval. Aberturas para a história da educação: do debate teórico metodológico no campo da história ao debate sobre a construção do sistema nacional de educação no Brasil. Campinas, SP: Autores Associados, 2013.

SAVIANI, Dermeval. Escola e democracia. Campinas, SP: Autores Associados, 2006.

SAVIANI, Dermeval. História das ideias pedagógicas no Brasil. Campinas, SP: Autores Associados, 2008b.

SAVIANI, Dermeval. Pedagogia histórico-crítica: Primeiras Aproximações. Campinas, SP: Autores Associados, 2008a.

SCHMIDT, Mario. Nova História Crítica: 6ª Série. São Paulo: Nova geração, 2002. p. 20.

VOVELLE, Michel. A História e a longa duração. In: LE GOFF, Jacques (Org.). A história nova. São Paulo: Martins Fontes, 1998.

\section{Notas}

\footnotetext{
${ }^{1}$ Mestre em Educação pela Universidade do Vale do Sapucaí-Univás. Professor de História no Ensino Fundamental da rede pública de Pouso Alegre/MG. Membro do Núcleo de Estudos e Pesquisas em Ética, Política e História da Educação Brasileira-NEPHEB. Correio eletrônico: alvaro_franco2007@ yahoo.com.br

${ }^{2}$ Doutora em Educação pela Universidade Federal de São Carlos-UFSCar. Professora de História da Educação Brasileira do curso Mestrado em Educação da Universidade do Vale do Sapucaí-Univás, em Pouso Alegre/MG. Líder do NEPHEB - Núcleo de Estudos e Pesquisas em Ética, Política e História da Educação Brasileira. Correio eletrônico: soniasiquelli@hotmail.com

${ }^{3}$ Este artigo é parte da dissertação de Mestrado em Educação, intitulada "Fontes Históricas e Ensino de História: Olhares sobre o Medievo", defendida em dezembro de 2014 no Mestrado em Educação, pela Universidade do Vale do Sapucaí-Univás. http://www.univas.edu.br/me/docs/dissertacoes2/7.pdf (acesso em 30/04/2016).

${ }^{4}$ Conceito cunhado pelo psicólogo suíço Carl Gustav Jung na primeira metade do século XX. Corresponde às experiências vivenciadas pela humanidade de modo geral, e que passam a compor o inconsciente pessoal de cada indivíduo.

${ }^{5}$ No estado de Minas Gerais, o supervisor pedagógico consiste no papel de coordenar os trabalhos dos professores dentro de cada unidade escolar.

${ }^{6}$ Esta pesquisa foi submetida ao CEP de Humanas /Univás/Pouso Alegre-MG, sob o protocolo número 391.304, de 09/09/2013.
}

Submetido em: 01/05/2016

Aprovado em: 06/11/2017 